\title{
1992/93 AMS/Industry Undergraduate Scholarships
}

In the fall of 1992, the American Meteorological Society joined with seven leading environmental science and service corporations to offer undergraduate scholarships in the atmospheric and related oceanic and hydrologic sciences. We would like to take this opportunity to once again thank the sponsoring corporations for their continued support of the AMS/In-

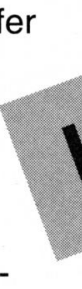

\section{Qualimetrics, Inc.}

Qualimetrics, Inc., a member of the Dynatech Corporation family of companies, has participated actively in meteorology for over 25 years, designing and manufacturing a variety of weather instruments and systems. Kathleen Louise Eyerman is a senior at the University of Oklahoma and will graduate with a degree in meteorology. She plans to continue on to a master's degree in the atmospheric sciences, looking toward a research career.

\section{Hughes STX Corporation}

Hughes STX Corporation, a subsidiary of Hughes Information Technology Company, provides multidisciplinary scientific and engineering services in space, earth, and environmental systems. Sharon B. Hauer is a senior at Purdue University and will receive a degree in atmospheric sciences. She plans to continue toward a Ph.D., and hopes to do research for NOAA or private industry in the field of atmospheric chemistry.

\section{Atmospheric and Environmental Research, Inc.}

Atmospheric and Environmental Research, Inc. has been a pioneer in atmospheric chemistry, climate change, radiative transfer, remote sensing, numerical weather prediction, and diagnostic studies of the atmosphere. Joseph W. Rohrbach is a senior at The Pennsylvania State University and will receive a degree in meteorology with a minor in mathematics.

\section{Aeromet Inc.}

Aeromet Inc. is a fast-growing meteorological services and instrumentation company that performs research, development, and operational meteorological support for the Department of Defense and NASA. dustry Undergraduate Scholarships Program. The corporations that joined with the Society in this program and the recipients of these scholarships are listed below. The recipients of the $\$ 4000$ scholarships received $\$ 2000$ in the fall of 1992, and will receive a subsequent $\$ 2000$ this fall as they enter their senior year.
Brian D. Skinner is a senior at the University of Oklahoma and will graduate with a degree in meteorology. His currents interests lie in severe storm forecasting and global climatology.

\section{Science and Technology Corporation}

Science and Technology Corporation is a leader in atmospheric science and related remote sensing research, development, and engineering activities. STC supports the global change initiative.Tina Louise Johnson is a senior at West Virginia University and will graduate with a degree in physical geography and a minor in physics. She will pursue a master's degree in meteorology.

\section{Campbell Scientific, Inc.}

Campbell Scientific, Inc. is a leading designer and manufacturer of environmental data acquisition instrumentation. It is a major supplier of automated weather stations, providing several telecommunication options for remote retrieval of data. John $\mathbf{J}$. Mewes is a senior at the University of North Dakota and will receive a degree in meteorology. He plans to work toward master's and Ph.D. degrees, eventually pursuing a career in research.

\section{Atmospherics Inc.}

Atmospherics Inc. has a worldwide reputation in weather modification operations and research, and has made global contributions in the development of and applications of science and technology. Jerald A. Brotzge is a senior at St. Louis University and will receive a degree in meteorology. He hopes to pursue research related to acid rain and ozone depletion.

${ }^{1}$ See coverage in Bull. Amer. Meteor. Soc., 73, 877-880. 